\title{
CFD and Experimental Analysis of Phase Change Material Behaviour Encapsulated in Internally Finned Spherical Capsule
}

\author{
G. Kumaresan 1,*, R. Santosh ${ }^{1}, H$. Revanth $^{2}$, G. Raju ${ }^{2}$, and S. Bhattacharyya ${ }^{3}$ \\ ${ }^{1}$ Department of Mechanical Engineering, CEG, Anna University, Chennai 600025, India \\ ${ }^{2}$ Global Nodes Engineering Solutions (P) Ltd, Chennai 600078, India \\ ${ }^{3}$ Mechanical \& Aeronautical Engineering Department, University of Pretoria, Hatfield 0028, South Africa
}

\begin{abstract}
Phase change material (PCM) based Thermal Energy Storage (TES) system is a proven technology to store/release a large amount of energy as latent heat during the phase transition process. In spite of the advantages, a major weakness with PCMs is their low thermal conductivity in both solid and liquid phases which seriously affects the heat transfer rate. Over the past two decades various efforts have taken place to enhance the heat transfer rate during the melting/solidification process of phase change material (PCM) encapsulated in various shape of containers. However, very few attempts have been made on accounting the heat transfer augmentation in internally finned spherical capsule. In the present study, CFD analysis is carried out to explore and report the effect of fin orientation on heat transfer enhancement of a paraffin PCM filled in an internally finned spherical capsule. Keeping the same surface area of fin but oriented differently (orthogonal and circumferential) in spherical capsule is undertaken for the computational analysis. In addition, spherical capsule with no fin configuration is also considered in the present analysis to compare with finned configuration results. The CFD results showed that the orthogonally finned spherical capsule resulted in appreciable reduction in total time taken for complete melting/ solidification process than the circumferential fin and no fin configuration. The same computational study is performed experimentally in order to validate the CFD results.
\end{abstract}

\section{Introduction}

In any LHTES system typically it entails the phase change material (PCM) and the heat transfer fluid (HTF). The PCMs which undergo melting and solidification when energy is exchanged with a heat transfer fluid. The PCMs are categorized as organic (paraffin's and non-paraffin's), inorganic (salt hydrates and metallic) and eutectics (organic eutectics and inorganic eutectics) [1]. Solid-liquid phase change during heat storage and recovery processes provides considerable advantages such as high energy storage capacity and near isothermal behavior during charging and discharging processes. Technical grade paraffin's have been recently used in a wide range of low thermal energy storage systems because of attractive thermophysical properties, ready availability and cheap $[2,3]$. However, the notable drawback of many PCMs including paraffin is their low thermal conductivity behavior which greatly suppresses the rate of heat transfer. Hence, heat transfer augmentation techniques are valuable for any LHTES applications.

PCMs are generally placed in containers for their effective usage over a longer period of time. There are several shapes of PCM packagings, such as plate, cylindrical, spherical, etc. $[4,5]$. In these shapes, the spherical containers are used most widely because it has the advantages of low volume to heat transfer surface area ratio and the ease of packing in the storage device [6]. Many authors studied experimentally and numerically the phase change behavior PCMs encapsulated in spherical capsule $[7,8]$. The inference from their study is that heat transfer time was lesser with smaller sizes of capsules. Apart from the selection of encapsulation material, geometry of encapsulation, heat transfer fluid (HTF) temperature and flow rate, the thermal performance of PCM based storage system can be significantly improved by the introduction of fins in containers/PCMs. Several experimental and or numerical studies were performed in recent years to report the impact of adding the fins internally/externally in the thermal performance of the TES system. Ren and Chan [9] numerically studied the impact of fin addition during the melting process of PCM by using the lattice Boltzmann method. The authors reported that the time taken for completing PCM melting got reduced with more number of fins, however the quantity of PCM stored in the encapsulation got reduced due to addition of more fins. Taghilou and Talati [10] conducted numerical study and reported that the addition of fins accelerated the melting process of the PCM and enhances the rate of heat transfer. The effect of fin number, natural convection on the PCM solidification time was numerically investigated by Jmal and Baccar

\footnotetext{
* Corresponding author: gkumaresan75@gmail.com
} 
[11]. They concluded that the enhancement in the PCM solidification is not much increased when a higher number of fins were used. Wang et al [12] investigated the PCM melting process in the sleeve tube with internal fins using FLUENT software and reported that the most effective angle between the adjacent fins is $60-90^{\circ}$ when natural convection is considered. Hariharan et al [13] experimentally and numerically analyzed the phase change behavior of paraffin PCM encapsulated in stainless steel spherical capsule.

Rathod and Banerjee [14] reported their experimental findings that the heat transfer rate of a PCM can be enhanced by the use of the introduction of longitudinal fins. It is understood from their results that incorporation of three longitudinal fins reduced the time taken for complete solidification of PCM by $43.6 \%$. Solomon and Velraj [15] experimentally studied the reduction in solidification time of PCM filled in a vertical finned cylindrical unit. They reported that the addition of fin and external cooling conditions together shifted the sub-cooling and phase change temperature range of the PCM. Kumaresan et al. [16] through their experimental investigations reported that orthogonal fins in spherical capsule showed better performance in terms of charging and discharging process over circumferential fin and no fin configuration.

It is also reported in the literature that, the enhancement in the thermal performance of the TES system can be achieved by the usage of lessing rings [17], metal matrices [18] and through the addition of nanoparticles/ microparticles [19,20].

The inference from the literature survey is that several techniques have been adopted to improve the heat transfer in the PCM based storage system. Further, it is understood that spherical container possesses better ratio of heat transfer surface area to volume compared to other encapsulation geometries. To the best of authors knowledge, no numerical attempts have been conducted yet to investigate the effect of orientation of fins placed in a spherical capsule. The main objective of the present work is to report the effect of incorporating the internal fins having different orientations (orthogonal and circumferential) on augmenting the heat transfer in spherically encapsulated PCM. The time taken for the complete melting and solidification of PCM during numerical is studied numerically for three spherical capsules and validation of CFD results with experimental analysis is reported in this paper.

\section{CFD Analysis}

A three-dimensional simulation study of phase change behavior of paraffin PCM encapsulated in a spherical container was carried out using the commercial Fluent 15.0 software. The physical model and computational procedure involved in the analysis are discussed below.

\subsection{Physical model}

The spherical capsule having a radius of $44 \mathrm{~mm}$ and 2 $\mathrm{mm}$ thickness is modeled by using commercial modeling software CATIA V5. The solid model of hemispherical capsule with and without fin is shown in Figure 1.
The paraffin PCM is considered to occupy the entire spherical capsule and constant wall boundary condition is employed for both melting $\left(75^{\circ} \mathrm{C}\right)$ and solidification $\left(30^{\circ} \mathrm{C}\right)$ process. The properties of the paraffin PCM is given in Table 1.

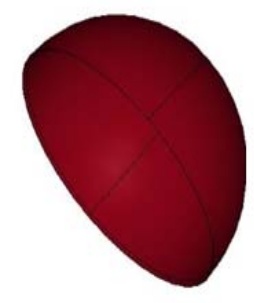

(a)

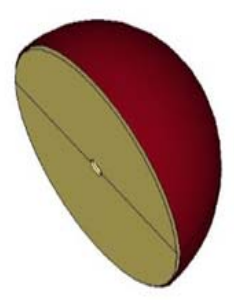

(b

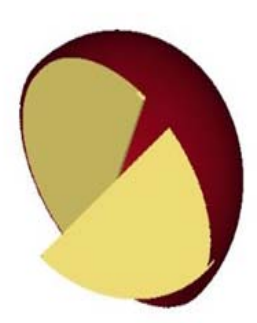

(c)
Fig. 1. Spherical capsule with different fin configurations (a) without fin (b) circumferentially finned spherical container (c) orthogonally finned spherical container.

Table 1. Properties of paraffin PCM

\begin{tabular}{|l|l|l|}
\hline Property & Solidification & Melting \\
\hline Latent heat & $137 \mathrm{~kJ} \mathrm{~kg}-1$ & $129 \mathrm{~kJ} \mathrm{~kg}-1$ \\
\hline Solidus temperature & $49^{\circ} \mathrm{C}$ & $50^{\circ} \mathrm{C}$ \\
\hline Liquidus temperature & $61^{\circ} \mathrm{C}$ & $63^{\circ} \mathrm{C}$ \\
\hline Density & $670 \mathrm{~kg} \mathrm{~m}^{-3}$ & \\
\hline Specific heat & $2000 \mathrm{~J} \mathrm{~kg}^{-1} \mathrm{~K}^{-1}$ \\
\hline Thermal conductivity & $0.24 \mathrm{~W} \mathrm{~m}^{-1} \mathrm{~K}^{-1}$ \\
\hline Dynamic viscosity & $0.004732 \mathrm{~kg} \mathrm{~m}^{-1} \mathrm{~s}^{-1}$ \\
\hline
\end{tabular}

The melting process is initiated by assigning the constant wall temperature of $75^{\circ} \mathrm{C}$ and at the same time $30^{\circ} \mathrm{C}$ temperature is considered for solid paraffin PCM. The state of the PCM after melting process is accounted for further solidification process however the new wall temperature of $30^{\circ} \mathrm{C}$ is assigned. The temperature considered for the CFD analysis during melting/solidification process is consolidated and given in Table 2.

Table 2. Initial and boundary conditions

\begin{tabular}{|l|l|l|}
\hline $\begin{array}{l}\text { Initial and Boundary } \\
\text { conditions }\end{array}$ & Solidification & Melting \\
\hline $\begin{array}{l}\text { Initial temperature of PCM } \\
\text { at time }=0\end{array}$ & $75^{\circ} \mathrm{C}$ & $30^{\circ} \mathrm{C}$ \\
\hline $\begin{array}{l}\text { Constant wall temp at } \\
\text { time }>0\end{array}$ & $30^{\circ} \mathrm{C}$ & $75^{\circ} \mathrm{C}$ \\
\hline
\end{tabular}

\subsection{Computational procedure}

The mathematical expression of energy equation (Eq. 1) that governs the physical phenomenon of phase change problem is given below:

$$
\frac{\partial}{\partial t}(\rho H)+\nabla \cdot(\rho \vec{v} H)=\nabla \cdot(k \Delta T)+S
$$

The phase change behavior of paraffin is done by using enthalpy-porosity formulation. In this method, the liquidsolid mushy zone is treated as a porous zone, with porosity equal to the liquid fraction. Hence, the mushy zone is a region in which the liquid fraction lies between 
0 and 1. The mushy zone is modeled as a 'pseudo' porous medium in which the porosity decreases from 1 to 0 as the material solidifies. When the material is fully solidified in a capsule, the porosity becomes zero. The effect of convection during the solidification of PCM process is negligible as the solidification layer formed during the initial process allows only conduction between the heat transfer fluid (HTF) and the liquid PCM present adjacent to the solidified front.

The first-order upwind scheme is used to discretize the governing equation of energy and the transient formulation is based on first-order implicit scheme. The convergence criteria for energy equation is maintained as the default value of $1 \times 10-7$. Timestep of 5 seconds is used for both solidification and melting processes, and the computations are carried out until the end of phase change process for all three spherical capsules. The overall time duration varies with respect to the different internally finned spherical configurations. The total number of iterations carried out per time step is assigned as 50 in the software.

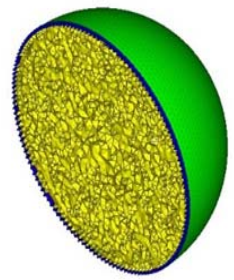

(a)

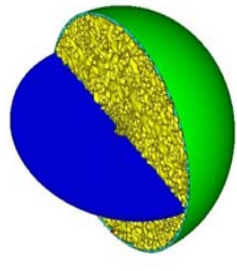

(b)

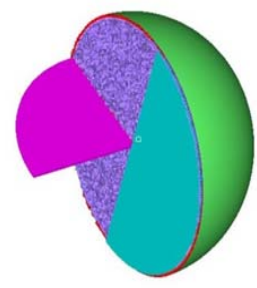

(c)
Fig. 2. Volume mesh cut sectional view (a) without fin (b) Circumferentially finned spherical container and (c) Orthogonally finned spherical container

Figure 2 shows the computational grid used for the present numerical investigation. The spherical surfaces and fins are meshed with triangular elements using HyperMesh software and the computational domain is discretized with tetrahedral elements. The required mesh refinements have been carried out near the fin region.

\section{Experimental Investigation}

The experimental validation of the computational study was carried out using an experimental set-up as shown in Figure 3. It consisted of a PCM encapsulated spherical capsule with stagnant therminol 55 oil (HTF) and was heated upto a required temperature with the help of an immersion type $2.0 \mathrm{~kW}$ capacity electric heater which was controlled by a thermostat. A known quantity (292 gm.) of paraffin PCM was filled inside the spherical capsule through an opening provided at the top such that it occupied a fill volume of about $90 \%$. The spherical capsules were made up of stainless steel material with internal diameter and wall thickness of $88 \mathrm{~mm}$. and 1 $\mathrm{mm}$. respectively. Six horizontal J-type thermocouples (accuracy $\pm 2.2^{\circ} \mathrm{C}$ ) were used to measure the temperature during experimentation and its position inside the spherical capsule is shown in Figure 3 (enlarged view of spherical capsule). The thermocouples T1, T2 and T3 are positioned in radial direction and $\mathrm{T} 4, \mathrm{~T} 5$ and $\mathrm{T} 6$ are positioned in axial direction respectively to ensure complete melting and solidification of PCM during the experimentation. The cylindrical tank was built using mild steel material that consisted of $0.053 \mathrm{~m} 3$ of oil with removable lid (340x100 mm.) fastened using bolts. A DC motor driven stirrer was inserted through a hole $(4 \mathrm{~mm}$.) on the lid and the PCM encapsulated spherical capsule was positioned at a height of about $150 \mathrm{~mm}$. from the bottom of the tank using 'O' shaped rings. Glass wool of $50 \mathrm{~mm}$. thickness was used to insulate the cylindrical tank and further insulation was provided by entrapping the air in the air gap (5, Figure 3) between the inner and outer concentric cylinders.

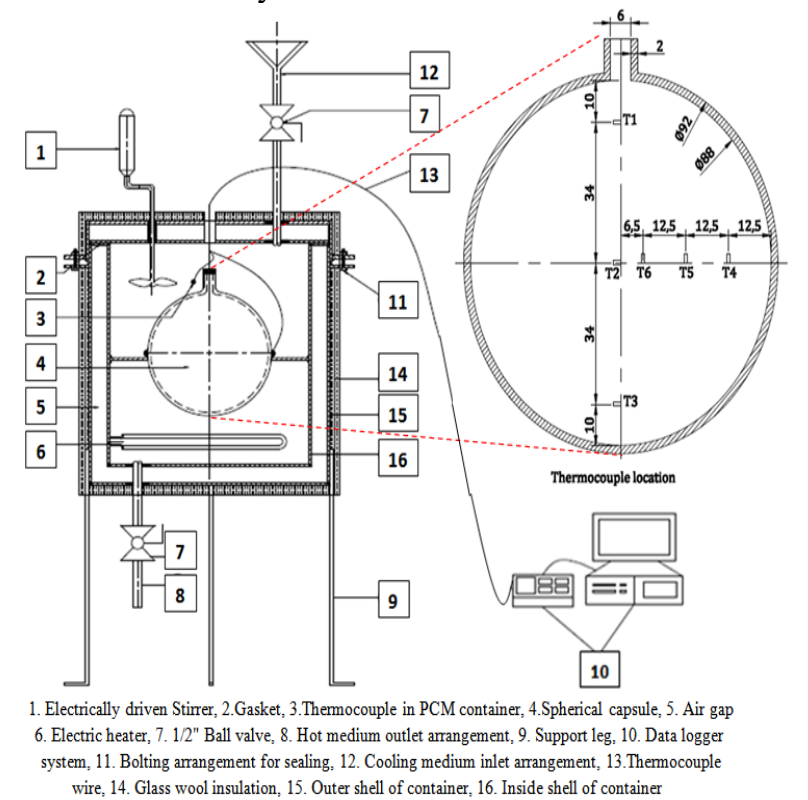

Fig. 3. Schematic diagram of the experimental setup

Experimentation involved the study of the temperature distribution inside the spherical capsule during the melting (charging) process and solidification (discharging) process respectively. Initially, the HTF at ambient temperature was filled inside the cylindrical tank and the temperature values were recorded using thermocouples and data acquisition system. Further, the HTF was heated upto $75^{\circ} \mathrm{C}$ and the charging process was carried out by maintaining a constant temperature of the HTF. During charging study, the heat energy is transferred from the HTF to the PCM which results in the rise of PCM temperature from ambient temperature. Once the PCM gets completely melted, the heater was switched off and the discharging process was executed with fresh oil at a constant HTF temperature of $30^{\circ} \mathrm{C}$. Due care was taken to ensure that $\mathrm{PCM}$ inside the spherical capsule got totally melted at $75^{\circ} \mathrm{C}$ during the start of each discharging process. The temperature values were recorded until the PCM got completely melted during charging process and completely solidified during discharging process respectively. The experimentation was repeated for all the three spherical configurations considered in the present study.

\section{Results and Discussion}




\subsection{CFD Results}

Figure 4 shows the liquid fraction obtained from the CFD results at various time intervals during melting process. It is inferred from Figure 4 (a) that the spherical capsule without fin takes 231 minutes to melt completely. Initially a thin layer of melting is observed closer to the wall. Later the liquid portion gradually increased and converges towards the centre to achieve completely liquid state. Figure 4 (b) shows the melting process inside the spherical capsule with circumferential fin. The total time taken during this melting process is 154.6 minutes. The presence of fin ensures the reduction in melting time while comparing with plain capsule configuration. Figure 4 (c) depicts the liquid fraction contour of the spherical capsule with orthogonal fin configuration. The total time taken for this case is 97.3 minutes which brings out a significant time reduction for complete melting duet to the presence of the orthogonal fins.

(a)
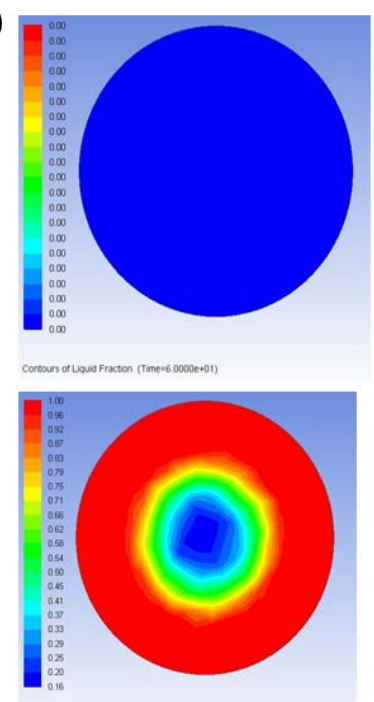

(b)
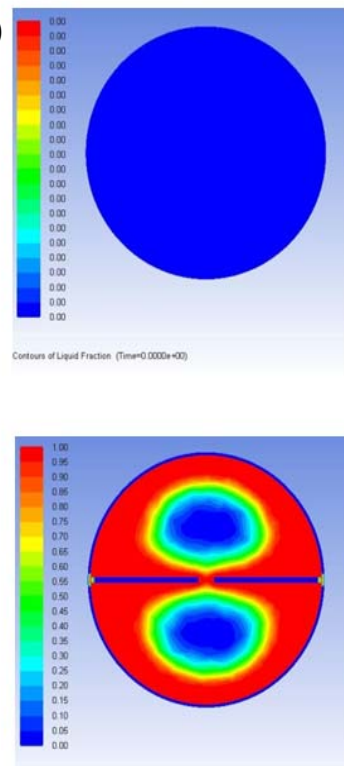
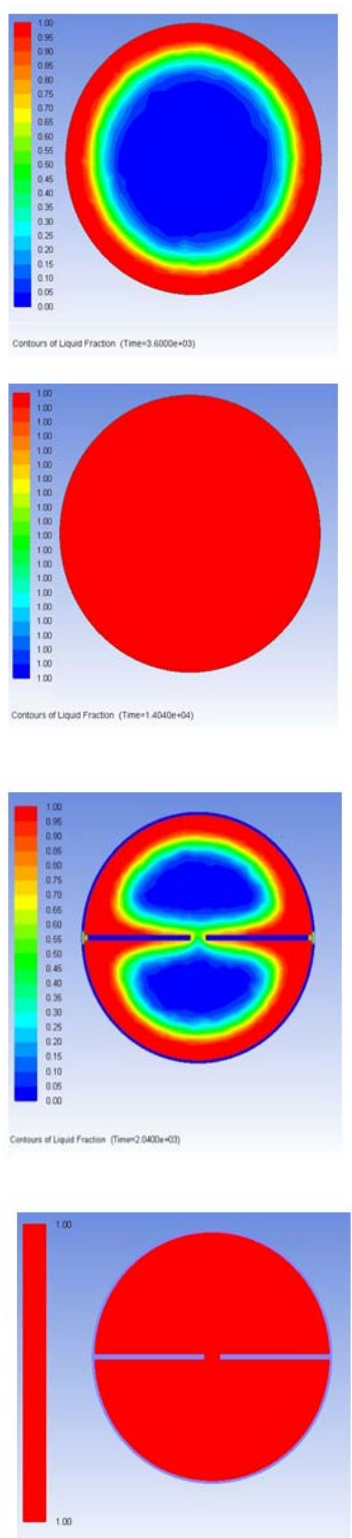

(c)
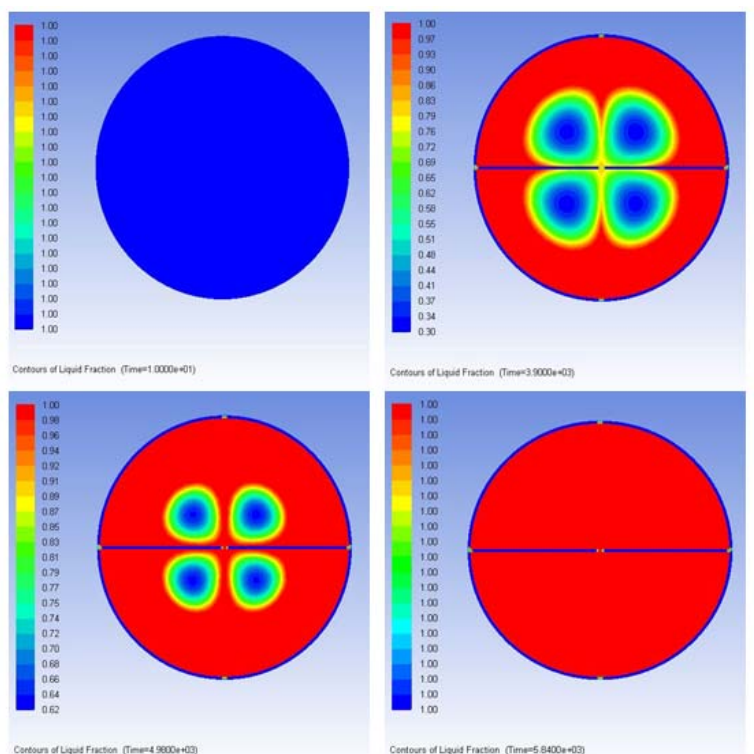

Fig. 4. Liquid fraction at various time interval during the melting process (a) without fin (b) Circumferentially finned spherical container (c) Orthogonally finned spherical container

Figure 5 shows the Liquid fraction obtained from the CFD results at various time interval during the solidification process. It is inferred from Figure 5 (a) that the spherical capsule without fin takes 125 minutes to solidify completely. Initially a thin layer of solidification is observed closer to the wall. Later the solid portion gradually increased and converges towards the centre to achieve completely solid-state. Figure 5 (b) shows the solidification process inside the spherical capsule with circumferential fin. The total time taken during this melting process is 72 minutes. The presence of fin ensures the reduction in solidification time while comparing with plain capsule configuration. Figure 5 (c) depicts the liquid fraction contour of the spherical capsule with orthogonal fin configuration. The total time taken for this case is 66.5 minutes. The time reduction for complete solidification is due to the presence of two mutually perpendicular fins inside the capsule.

(a)
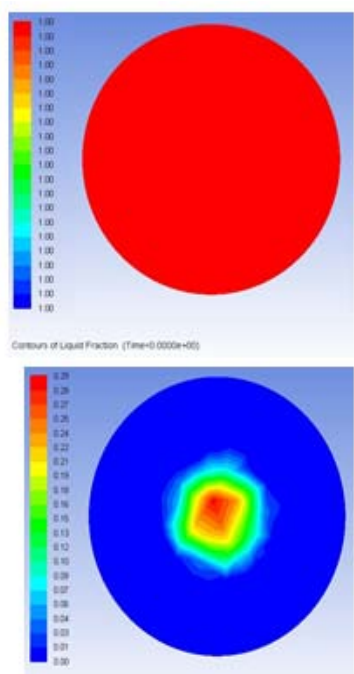

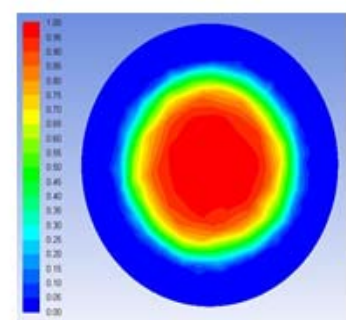

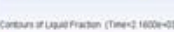

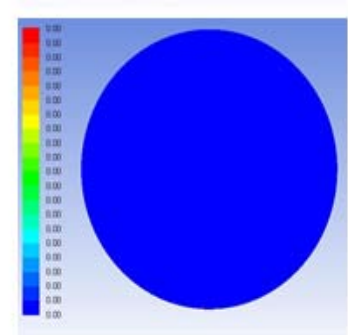


(b)
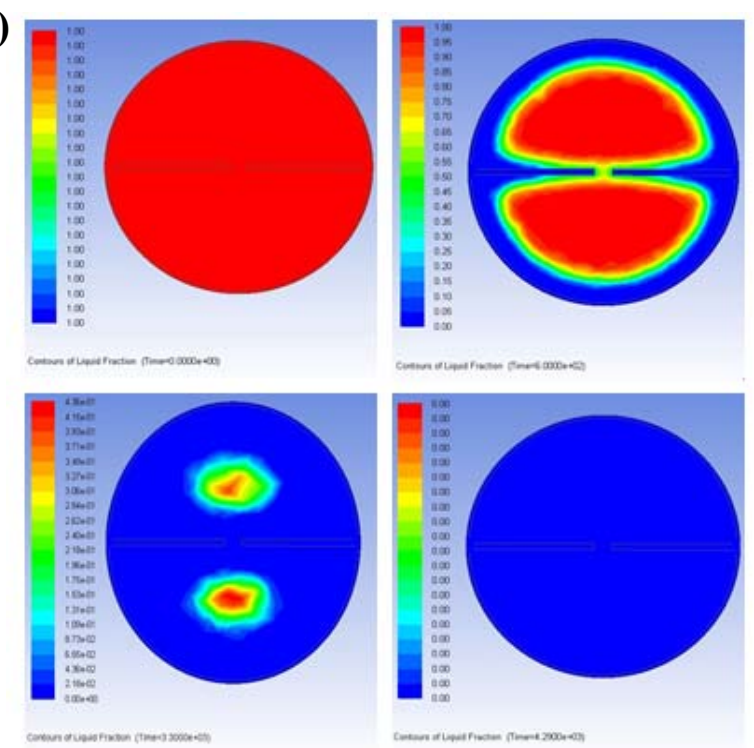

(c)
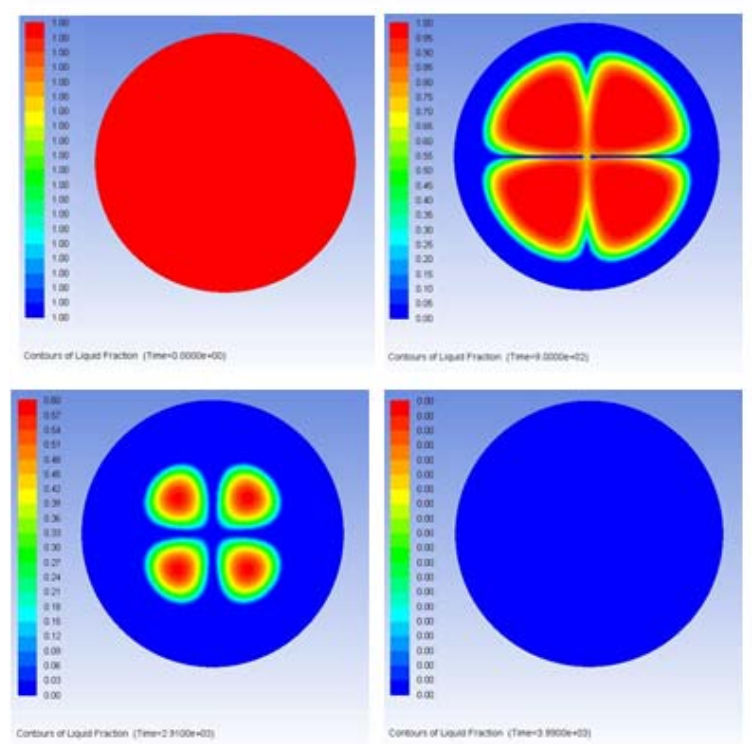

Fig. 5. Liquid fraction at various time interval during solidification process (a) without fin (b) Circumferentially finned spherical container (c) Orthogonally finned spherical container

\subsection{Experimental Results}

Figure 6 shows the comparison between the obtained CFD and experimental results depicting the total time taken for the complete melting and solidification processes of the PCM. From the experimental analysis it was found that the melting and solidification time during the charging and discharging process was minimum in the case of spherical capsule with orthogonal fins compared to no fin and circumferential fin configurations. The time taken for complete melting during the experimental charging process was found to be about 205 minutes, 105 minutes and 70 minutes for no fin, circumferential fin and orthogonal fin configurations respectively. Similarly the time taken for complete solidification was found to be 90 minutes, 65 minutes and 55 minutes respectively.

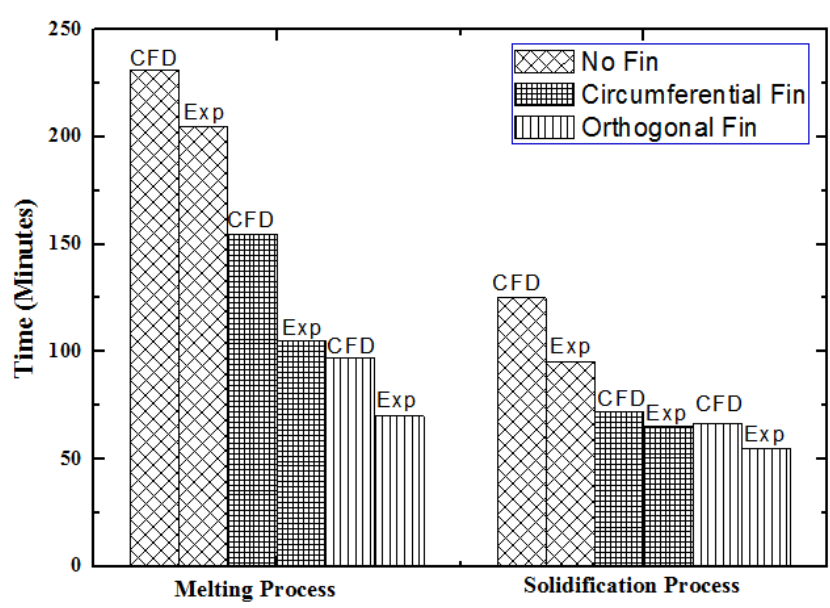

Fig. 6. Comparison of PCM temperature during melting and solidification process

It can be observed that the total time taken for the complete melting and solidification process in the CFD analysis is higher compared to experimental results. The deviation in the time duration can be attributed to the following reasons: 1 . The natural convection process and its effect on the enhancement of heat transfer during the PCM melting process were unaccounted during CFD analysis. 2. Considering the volumetric expansion that occurs during the experimental phase change process, the fill volume of the PCM was restricted to $90 \%$ of the actual volume of the spherical capsule. This effect could contribute to about $10 \%$ reduction in the experimental time compared to CFD analysis. 3. Further errors could be due to the effect of thermocouple sheath material which itself transfers heat energy from the walls of the spherical container to the filled PCM material at a faster rate. Further from Figure 6 it can be observed that the solidification process is quicker than the melting process due to high thermal conductivity property of the solid PCM over liquid PCM.

\section{Conclusion}

The numerical study of the influence of internal fin orientation in a spherical capsule is investigated in detail in this work. The melting and solidification process of paraffin PCM encapsulated in orthogonally finned spherical capsule and circumferentially finned spherical capsule is investigated and the results of time taken during phase change process is compared with no fin spherical capsule. The time taken to reach liquid fraction 1 of PCM for orthogonal fin is $37.0 \%$ and $57.8 \%$ is lesser than circumferential and no fin configuration respectively. The time taken to reach liquid fraction 0 of PCM for orthogonal fin is $7.6 \%$ and $46.8 \%$ is lesser than circumferential and no fin configuration respectively. Thus it is very evident from the results that the presence of orthogonal fin in spherical capsule increases the melting and solidification rates significantly when compared to circumferential fin though this fin having the same fin surface area of orthogonal fin. The result of the analysis shows that the solidification process is faster 
than the melting process which is due to the higher thermal conductivity of the solid PCM. The time taken during computational analysis for phase change activity of PCM stored in these spherical containers is validated with experimental results and justification for deviation is also discussed.

\section{References}

[1] Souayfane F, Fardoun F, and Biwole P H: Phase change materials (PCM) for cooling applications in buildings: A review, Energy and Buildings, 129, pp. 396-431, 2016.

[2] Agarwal A, and Sarviya R M: An experimental investigation of shell and tube latent heat storage for solar dryer using paraffin wax as heat storage material, Engineering Science and Technology, 19, pp. 619-631, 2016.

[3] Alva G, Liu L, Huang X, and Fang G: Thermal energy storage materials and systems for solar energy applications, Renewable and Sustainable Energy Reviews, 68, pp. 693-706, 2017.

[4] Ismail K A R, da Silva M G E: Melting of PCM around a horizontal cylinder with constant surface temperature, International Journal of Thermal Science, 2003,42, pp. 1145-1152.

[5] Assis E, Katsman L, Ziskind G, Letan R: Numerical and experimental study of melting in a spherical shell, International Journal of Heat and Mass Transfer, 2007,50, pp. 1790-1804.

[6] Bilir L, Ilken Z: Total solidification time of a liquid phase change material enclosed in cylindrical/spherical container, Applied thermal engineering, 2005, 25, pp. 1488-1502.

[7] Tan F L, Hosseinizadeh S F, Khodadadi J M, Fan LW. Experimental and computational study of constrained melting of phase change materials (PCM) inside a spherical capsule, International Journal of Heat and Mass Transfer, 2009, 52, pp. 3464-3472.

[8] Zhao W, Neti S, Oztekin A: Heat transfer analysis of encapsulated PCM, Applied Thermal Engineering,2013, 50, pp. 143-151.

[9] Ren Q, Chan C L: GPU accelerated numerical study of PCM melting process in an enclosure with internal fins using lattice Boltzmann method, International Journal of Heat and Mass Transfer, 2016, 100, pp. 522-535.

[10] Taghilou M, Talati, F: Numerical investigation on the natural convection effects in the melting process of PCM in a finned container using lattice Boltzmann method, International Journal of Refrigeration, 2016, 70, pp. 157-170.

[11] Jmal I, Baccar M: Numerical study of PCM solidification in a finned tube thermal storage including natural convection, Applied Thermal Engineering, 2015, vol.84, pp. 320-330.

[12] Wang P, Yao H, Lan Z, Peng Z, Huang Y, Ding Y: Numerical investigation of PCM melting process in sleeve tube with internal fins, Energy Conservation and Management, 2016, 110, pp. 428-435.
[13] Hariharan K, Senthil Kumar G, Kumaresan G, Velraj R: Investigation on Phase Change Behavior of Paraffin Phase Change Material in a Spherical Capsule for Solar Thermal Storage Units, Heat Transfer Engineering, 2017, DOI:10.1080/01457632.2017.1341227.

[14] Rathod M K, Banerjee J: Thermal performance enhancement of shell and tube Latent heat storage unit using longitudinal fins, Applied Thermal Engineering, 2015, 75, pp. 1084-1092.

[15] Solomon G R, Velraj R: Analysis of the heat transfer mechanisms during energy storage in a Phase change material filled vertical finned cylindrical unit for free cooling application, Energy Conservation and Management, 2013, 75, pp. 466-473.

[16] Kumaresan G, Karthik P, Denkenberger D C, Velraj R: Effect of Fin Orientations in a Spherically Encapsulated Phase Change Materials for Effective Heat Transfer Enhancement, Chemical Engineering Transactions, 2017, 62, pp. 277-282.

[17] Velraj R, Seeniraj R V, Hafner B, Faber C, Schwarzer K: Heat transfer enhancement in a latent heat storage system, Solar Energy, 1998, 65, pp. 171-180.

[18] Ettouney H, Alatiqi I, Al-Sahali M, Al-Hajirie K: Heat transfer enhancement in energy storage in spherical capsules filled with paraffin wax and metal beads, Energy Conservation and Management, 2006, 47, pp. 211-228.

[19] Kumaresan V, Velraj R, Das S K: The effect of carbon nanotubes in enhancing the thermal transport properties of PCM during solidification, Heat and Mass Transfer, 2012, 48, pp. 1345-1355.

[20] Pramothraj M, Santosh R, Swaminathan M R, Kumaresan G: Study of effect of $\mathrm{Al}$ and $\mathrm{Cu}$ microparticles dispersed in D-Mannitol PCM for effective solar thermal energy storage, Journal of Thermal Analysis and Calorimetry, 2019, pp. 110. DOI: $10.1007 / \mathrm{s} 10973-019-08469-1$. 